\title{
Evaluation of Anti-Biofilm Capability of Cordycepin Against Candida albicans
}

This article was published in the following Dove Press journal:

Infection and Drug Resistance

\author{
Yu Wang (iD) $1,2, *$ \\ Zejun $\mathrm{Pei}^{1,2 *}$ \\ Zaixiang Lou $^{2}$ \\ Hongxin Wang ${ }^{2}$ \\ 'The Affiliated Wuxi No. 2 People's \\ Hospital of Nanjing Medical University, \\ Wuxi, 2I4I22, People's Republic of \\ China; ${ }^{2}$ School of Food Science and \\ Technology, Jiangnan University, Wuxi, \\ 214122, People's Republic of China
}

*These authors contributed equally to this work
Correspondence: Zaixiang Lou

Tel +86-1875I559780

Email louzaixiang@126.com

Zejun Pei

Tel +86-5I 0-68563496

Email 455632172@qq.com
Introduction: The opportunistic pathogen Candida albicans can form biofilms, resulting in drug resistance with great risk to medical treatment.

Methodology: We investigated the ability of $C$. albicans to form biofilms on different materials, as well as the inhibitory and eradicating effects of cordycepin on biofilm. The action mechanism of cordycepin against biofilm was studied by crystal violet staining, XTT [2, 3-bis (2-methoxy-4-nitro-5-sulfophenyl)-2H-tetrazolium-5-carboxanilide] reduction method, phenol-sulfuric acid method, cellular superficial hydrophobicity (CSH) assay, and confocal laser scanning microscope observation. We also evaluated the acute toxicity of cordycepin in vivo.

Results: The results showed facile formation of biofilms by $C$. albicans on polypropylene. The $50 \%$ minimum inhibitory concentration $\left(\mathrm{MIC}_{50}\right)$ of cordycepin was $0.062 \mathrm{mg} / \mathrm{mL}$. A concentration of $0.125 \mathrm{mg} / \mathrm{mL}$ significantly decreased biofilm formation, metabolic activity, secretion of extracellular polysaccharides, and relative $\mathrm{CSH}$. Cordycepin could inhibit biofilm formation at low concentration without affecting fungal growth. In addition, cordycepin effectively eradicated $59.14 \%$ of mature biofilms of C. albicans at a concentration of $0.5 \mathrm{mg} / \mathrm{mL}$. For acute toxicity, the $\mathrm{LD}_{50}(50 \%$ of lethal dose $)$ of cordycepin was determined as higher than $500 \mathrm{mg} / \mathrm{kg}$ for mice.

Conclusion: The results of this study show that cordycepin significantly inhibited and eradicated biofilms by decreasing metabolic activity, the ratio of living cells, the hydrophobicity, and damaging the extracellular polysaccharides of biofilm. These findings should facilitate more effective application of cordycepin and suggest a new direction for the treatment of fungal infections.

Keywords: cordycepin, Candida albicans, biofilm, inhibition, eradication

\section{Introduction}

Candida albicans is normally commensal on human mucosal surfaces, but can become an opportunistic pathogen causing infections at various levels, ranging from superficial to life-threatening systemic infections. ${ }^{1}$ At present, fluconazole, nystatin, amphotericin B, and echinocandin are mainly used for clinical treatment. $^{2-5}$ However, with few traditional antifungal drugs and the challenges of long-term use of these drugs, drug resistance is gradually increasing. The ability of $C$. albicans to form biofilms is an important factor in its resistance to treatment, and the resistance of fungal biofilms can be 1000 times higher than that of free microorganisms. ${ }^{6}$ A biofilm is a microbial community that is embedded in a selfproduced extracellular matrix and adsorbed on the surface of an object. ${ }^{7}$ The extracellular matrix helps preserve the biofilm structure and protects cells from 
host defenses and drug attacks. ${ }^{8,9}$ Given the effect of biofilm formation to promote drug resistance and the limitations of existing drugs, such as the substantial toxicity of amphotericin B, there is an urgent need for natural alternatives. $^{4}$

Cordycepin, also known as $3^{\prime}$-deoxyadenosine, is a nucleoside analogue that is extracted from Cordyceps militaris. ${ }^{10}$ Cordycepin is structurally similar to adenosine, but lacks the 3'-hydroxyl group, which increases its efficacy. Cordycepin has some biological activities such as antimicrobial, anti-tumor, anti-inflammatory, and immunomodulation. ${ }^{11-14}$ The antimicrobial activity of cordycepin is broad-spectrum and can inhibit eight kinds of lactic acid bacteria and 11 kinds of intestinal bacteria. ${ }^{15}$ Sugar and McCaffrey characterized the antifungal activity of cordycepin using in vivo experiments. ${ }^{16}$ The antimicrobial mode of cordycepin has been studied, with the drug affecting multiple processes such as the uptake of cordycepin through the nucleoside transporter of $C$. albicans, followed by binding to hydrophobic bases or phosphate groups of DNA to alter the structure and function of the microbial nucleic acids, eventually leading to cell death. ${ }^{17,18}$ However, most work has focused on the effects of cordycepin on planktonic microorganisms, with no investigation of the effect of cordycepin on $C$. albicans biofilm. ${ }^{15,17}$ In this study, we investigated the effects of cordycepin on the formation and elimination of C. albicans biofilm and determined the action mechanism to enable more effective application of cordycepin.

\section{Materials and Methods}

\section{Materials, Strains and Growth Conditions}

Cordycepin $(\geq 98 \%)$ and fluconazole $(96 \%)$ were purchased from the Aladdin Biochemical Technology Co., Ltd. (Shanghai, China). The strains, C. albicans, Candida tropicalis, Candida glabrata and Candida parapsilosis were clinically isolated strains provided by the clinical laboratory of Wuxi No. 2 People's Hospital. Antifungal susceptibility test was also performed using C. albicans standard strains (BNCC 186382, ATCC 10231, and CMCC 98001). C. albicans BNCC 186382 was purchased from Beina Chuanglian Biotechnology Co., Ltd. (Beijing, China), and other standard strains were purchased from Guangdong Huankai Microbial Technology Co., Ltd. (Guangdong, China). The strains were identified by automatic microbial mass spectrometry detection system (bioMerieux, VITEX MS, France) and stored in a glycerol tube at $-80^{\circ} \mathrm{C}$. The strains were cultivated to the exponential phase in potato dextrose broth (PDB, Hangzhou Baisi Biotechnology Co., Ltd, Hangzhou, China) before use.

\section{Determination of Minimum Inhibitory Concentration (MIC) of Cordycepin}

The MIC was determined using the standard broth microdilution method as previously described in document M27 published by the Clinical and Laboratory Standards Institute. ${ }^{19}$ One hundred microliters of drug solution was added to the first column of wells and then was twofold serial diluted in RPMI-1640 medium (Hangzhou Baisi Biotechnology Co., Ltd, Hangzhou, China), buffered with $165 \mathrm{mM}$ 3-(N-morpholino) propanesulfonic acid (MOPS, Beijing Solarbio Science \& Technology Co., Ltd, Beijing, China), $\mathrm{pH}$ 6.5, with initial concentrations of cordycepin and fluconazole of 2 and $0.064 \mathrm{mg} / \mathrm{mL}$, respectively. Fungal suspensions were then diluted in RPMI-1640 medium and added to each well at a final concentration of $10^{3}$ cells $/ \mathrm{mL}$. The well plate was incubated at $35^{\circ} \mathrm{C}$ for 48 h. The document M27 states that MIC endpoint of fluconazole and flucytosine is the lowest concentration that inhibited $50 \%$ of the fungal yeast growth in relation to control $\left(\mathrm{MIC}_{50}\right) .{ }^{19}$ Flucytosine is a nucleotide-analogue antibiotic with a mechanism of disturbing protein and DNA synthesis. ${ }^{20}$ Here, we considered $\mathrm{MIC}_{50}$ as the MIC endpoint of cordycepin due to the similar mechanism and structural characteristics of cordycepin and flucytosine.

\section{Effects of Cordycepin on the Growth of C. albicans}

The C. albicans suspensions were inoculated into $50 \mathrm{~mL}$ of RPMI-1640 medium to obtain a final concentration of $10^{5}-10^{6}$ cells $/ \mathrm{mL}$, and different concentrations of cordycepin $(0.16,0.31,0.062$, and $0.125 \mathrm{mg} / \mathrm{mL})$ were added at the same time. The mixture was incubated at $35^{\circ} \mathrm{C}$ and $150 \mathrm{rpm}$ for $48 \mathrm{~h}$. During this period, absorbance changes at $600 \mathrm{~nm}$ were recorded at regular intervals. ${ }^{21}$

\section{The Ability of C. albicans to Form Biofilms on Different Materials}

Crystal violet staining was used in this assay to evaluate the effect of different materials on the biofilm formation of C. albicans. ${ }^{22}$ Stainless steel, plastic polypropylene and glass were divided into $25 \times 25 \times 1 \mathrm{~mm}$ square pieces 
and soaked in $75 \%$ ethanol overnight. The materials and the cell suspensions with a final concentration of $10^{6}$ cells/ $\mathrm{mL}$ were incubated in a 6-well plate at $35^{\circ} \mathrm{C}$ for 24 $\mathrm{h}$ without shaking to form a biofilm. ${ }^{23}$ After that, the well plate was washed three times by phosphate-buffered saline (PBS, $\mathrm{pH}=6.5$ ). The attached cells were fixed by drying at $60^{\circ} \mathrm{C}$ for $30 \mathrm{~min}$, and then, $4 \mathrm{~mL}$ of $0.1 \%(\mathrm{w} / \mathrm{v})$ crystal violet was added and left for $5 \mathrm{~min}$. Excess staining solution was removed by washing three times with PBS. The stain retained by the biofilm was dissolved in $4 \mathrm{~mL}$ of $33 \%(\mathrm{v} / \mathrm{v})$ glacial acetic acid. After $10 \mathrm{~min}$, the solution in the treated plate was transferred to a clean 96-well plate, and the OD value was measured at $595 \mathrm{~nm}$.

\section{Analysis of the Effects of Cordycepin on the Formation of $C$. albicans Biofilm}

The cell suspensions were co-cultured with different concentrations of cordycepin, and the final concentrations of cordycepin were $0.16,0.031,0.062$, and $0.125 \mathrm{mg} / \mathrm{mL}$, with no addition of cordycepin as control. Then, the well plates were incubated at $35^{\circ} \mathrm{C}$ for $24 \mathrm{~h}$. The final data were calculated according to the formula:

$$
\text { Inhibition }(\%)=\frac{\mathrm{OD}_{\text {control }}-\mathrm{OD}_{\text {sample }}}{\mathrm{OD}_{\text {control }}} \times 100 \%
$$

\section{Analysis of the Effects of Cordycepin on the Pre-Formed Biofilms}

The mature biofilms of $C$. albicans were pre-formed by adding only cell suspensions and culturing at $35^{\circ} \mathrm{C}$ for 24h. After incubation, the non-adherent cells were removed by washing with PBS, and RPMI-1640 medium containing different concentrations of cordycepin was added to the well plate, in which the final concentration of cordycepin was $0.62,0.125,0.25$, and $0.5 \mathrm{mg} / \mathrm{mL}$, respectively. The well plate was covered with its lid and incubated at $35^{\circ} \mathrm{C}$ for an additional $4 \mathrm{~h}$. The final data were calculated according to the formula:

$$
\text { Eradication }(\%)=\frac{\mathrm{OD}_{\text {control }}-\mathrm{OD}_{\text {sample }}}{\mathrm{OD}_{\text {control }}} \times 100 \%
$$

\section{Quantification of Biofilm}

Quantification of biofilm was also analyzed by crystal violet staining assay. ${ }^{22}$ After incubated for an appropriate time, the 96-well plates were washed three times and dried at $60^{\circ} \mathrm{C}$ for $30 \mathrm{~min}$, then $200 \mu \mathrm{L}$ of $0.1 \%$ (w/v) crystal violet solution was added to each well for staining. The stain retained by the biofilm was dissolved in $200 \mu \mathrm{L}$ of $33 \%$ glacial acetic acid and the OD value was measured at $595 \mathrm{~nm}$.

\section{Measurement of the Metabolic Activity of Biofilm}

The biofilm metabolic activity of the biofilm was detected using standard XTT [2, 3-bis (2-methoxy-4-nitro-5-sulfophenyl)-2H-tetrazolium-5-carboxanilide] (Aladdin, Shanghai, China) reduction assay. ${ }^{24}$ XTT solution $(1 \mathrm{mg} /$ $\mathrm{mL}$ ) was prepared in sterile distilled water and menadione solution (1 mmol/L, Aladdin, Shanghai, China) was dissolved in acetone. After the plate was washed three times with PBS, $54 \mu \mathrm{L}$ of menadione/XTT mixed solution (menadione: $\mathrm{XTT}=1: 12.5$ ) was added to each well, and the reaction was carried out at $35^{\circ} \mathrm{C}$ for $2 \mathrm{~h}$ in the dark. The absorbance at $490 \mathrm{~nm}$ was measured.

\section{Analysis of the Extracellular Polysaccharide (EPS)}

EPS was extracted by previously reported methods. ${ }^{25,26}$ Briefly, C. albicans suspensions ( $1 \%, \mathrm{v} / \mathrm{v})$ were transferred to the fresh culture medium, and after treatment with cordycepin, the suspensions were centrifuged at 4, 000 $\times \mathrm{g}$ for $10 \mathrm{~min}$ to remove the cells. The EPS in the supernatant was then precipitated in $80 \%(\mathrm{v} / \mathrm{v})$ cold ethanol and stored at $4^{\circ} \mathrm{C}$ overnight. The supernatant was removed after centrifugation at $8,000 \times \mathrm{g}$ for $20 \mathrm{~min}$ at $4^{\circ} \mathrm{C}$. For polysaccharide precipitation, $1 \mathrm{~mL}$ of $0.5 \%$ phenol and $5 \mathrm{~mL}$ of sulfuric acid were added to each experimental group at the same rate. Afterward, the tubes were allowed to stand for $10 \mathrm{~min}$ and then the solution appeared red when maintained in a boiling water bath for $15 \mathrm{~min}$. Changes in EPS could be quantified through the value of $\mathrm{OD}_{490 \mathrm{~nm}}$.

\section{Observation of Biofilm by Confocal Laser Scanning Microscopy (CLSM)}

C. albicans suspensions were added into a 6-well plate containing a sterilized coverslip and medium. Cordycepin was added at different time points. One group was that cordycepin was added at the beginning and incubated with C. albicans for $24 \mathrm{~h}$. The other group was that cordycepin was added after $24 \mathrm{~h}$ and then incubated for $4 \mathrm{~h}$. The coverslips were washed three times to remove unadhered microorganisms. Immediately after the excess water was aspirated, $5 \mu \mathrm{L}$ of fluorescein isothiocyanate (FITC) Cona 
(Sigma Aldrich, UK) was added and stained for $30 \mathrm{~min}$ at $4^{\circ} \mathrm{C}$. Then $5 \mu \mathrm{L}$ of propidium iodide (PI, Aladdin, Shanghai, China) solution was added at the same position and stained for $15 \mathrm{~min}$ at $4{ }^{\circ} \mathrm{C}$. At the same time, $20 \mu \mathrm{L}$ of a mixed solution of fluorescein diacetate (FDA, Aladdin, Shanghai, China) and PI (FDA:PI $=1: 1$ ) was added to another set of coverslips and stained for $15 \mathrm{~min}$ at room temperature. CLSM (ZEISS, Germany) was used to observe the coverslip that has been placed on the slide. ${ }^{22,27}$

\section{Cellular Surface Hydrophobicity (CSH) Assay}

CSH analysis was based on water-hydrocarbon interface analysis as described by Stephen and Sardi et al. ${ }^{28,29}$ The drug-treated fungal suspensions were washed twice and resuspended in PBS solution (denoted as $\mathrm{A}_{0}, \mathrm{OD}_{600}=$ 0.4-0.6). One milliliter of toluene was added to $1.5 \mathrm{~mL}$ of the suspension. Thereafter, the mixture was vortexed for $2 \mathrm{~min}$ and allowed to stand for $10 \mathrm{~min}$. Finally, the lower aqueous phase was taken with a syringe to determine the OD value $\left(A_{1}\right)$ at $600 \mathrm{~nm}$. Cells in RPMI-1640 medium without toluene were used as negative controls. The relative CSH was expressed as the percentage drop in optical density of the test suspension compared with the negative control. ${ }^{30}$ The formula was:

$$
\text { Relative } \operatorname{CSH}(\%)=\frac{A_{0}-A_{1}}{A_{1}} \times 100 \%
$$

\section{Acute Toxicity}

All animal studies were approved by the Laboratory Animals Ethics Committee of Jiangnan University and carried out in compliance with national and international (Declaration of Helsinki) guidelines. For the acute toxicity test, the $30 \mathrm{KM}$ mice $(18-22 \mathrm{~g})$ purchased from Shanghai SLAC Laboratory Animal Co., Ltd. (Beijing, China) were separated into three groups as $500 \mathrm{mg} / \mathrm{kg}, 250 \mathrm{mg} / \mathrm{kg}$, and PBS control group $(n=10)$. The mice were fasted overnight and then administered. After that, the mice's weight, mental state, hair condition and death were daily observed for 14 days.

\section{Statistical Analysis}

Statistical analysis was performed using SPSS 20.0 statistical software. Data were expressed as mean \pm standard deviation and analyzed by one-way analysis of variance (AVONA). A $p$-value below 0.05 was considered statistically significant.

\section{Results \\ MICs of Cordycepin}

Cordycepin was tested for its antifungal activity against Candida pathogens, and the MIC values of cordycepin are listed in Table 1. Cordycepin exhibited antifungal activity against the tested strains, and the antifungal activity of cordycepin against $C$. albicans was higher than that against $C$. parapsilosis, C. glabrata, and C. tropicalis. To further evaluate the inhibitory effect of cordycepin on C. albicans, fluconazole was used as a positive control. The $\mathrm{MIC}_{50}$ values of fluconazole against standard and clinically isolated $C$. albicans strains were $\leq 0.002$ and $0.032 \mathrm{mg} / \mathrm{mL}$, and the antifungal activity of fluconazole against $C$. albicans standard strains was consistent with the value determined in a previous study. ${ }^{3}$ According to the breakpoints for in vitro broth dilution susceptibility testing of C. albicans in CLSI document M60 that sets the $\mathrm{MIC}_{50}$ of fluconazole against C. albicans as $\leq 0.002 \mathrm{mg} /$ $\mathrm{mL}$, the strain is susceptible to fluconazole. When $\mathrm{MIC}_{50}=$ $0.004 \mathrm{mg} / \mathrm{mL}, C$. albicans is susceptible-dose dependent to fluconazole. When $\mathrm{MIC}_{50} \geq 0.008 \mathrm{mg} / \mathrm{mL}, C$. albicans is resistant to fluconazole. ${ }^{31}$ Therefore, the clinical C. albicans isolate was resistant to fluconazole, but the standard strains were susceptible. For the next tests, the clinical isolate of $C$. albicans was selected.

\section{Effects of Cordycepin on the Growth of C. albicans}

The effects of cordycepin on the growth of C. albicans were tested by measuring the optical density of fungal culture at $600 \mathrm{~nm}$ in the presence or absence of cordycepin, as shown in Figure 1. In the absence of cordycepin,

Table I MIC Values of Cordycepin and Fluconazole

\begin{tabular}{|l|l|l|}
\hline Drugs & Species & MIC $_{\mathbf{5 0}}(\mathrm{mg} / \mathrm{mL})$ \\
\hline Cordycepin & C. albicans BNCC I86382 & 0.062 \\
& C. albicans ATCC I023I & 0.062 \\
& C. albicans CMCC 9800I & 0.031 \\
& C. albicans & 0.062 \\
& C. tropicalis & 0.125 \\
& C. glabrata & 0.125 \\
& C. parapsilosis & 0.25 \\
& Species & MIC \\
& Fl (mg/mL) \\
\hline \multirow{2}{*}{ Cluconazole } & C. albicans BNCC I86382 & 0.001 \\
& C. albicans ATCC 1023I & 0.002 \\
& C. albicans CMCC 9800I & 0.002 \\
& C. albicans & 0.032 \\
\hline
\end{tabular}




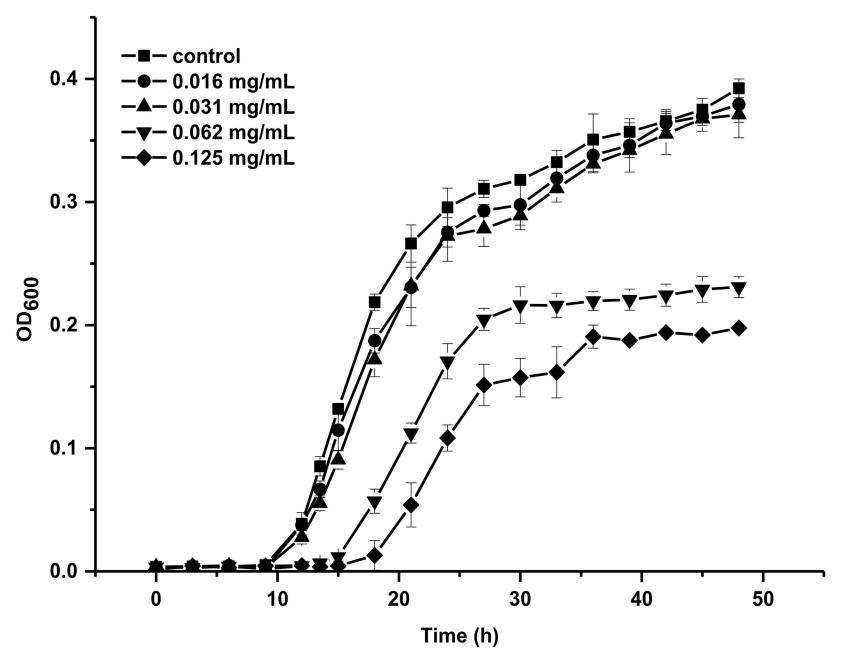

Figure I Growth curves of C. albicans in the absence or presence cordycepin.

C. albicans reached exponential phase within $9 \mathrm{~h}$. At concentrations of 0.031 and $0.016 \mathrm{mg} / \mathrm{mL}$, there were no significant effects on the growth of $C$. albicans compared with the control $(\mathrm{P}>0.05)$. For concentrations of 0.062 and $0.0125 \mathrm{mg} / \mathrm{mL}$, the growth of $C$. albicans was significantly inhibited $(\mathrm{P}<0.05)$.

\section{Effects of Different Materials on the Ability of $C$. albicans to Form Biofilms}

Plastic, glass, and stainless steel materials are commonly used to make various medical devices that are used in hospitals. Pathogenic fungi can form biofilms and attach to devices including intravenous catheters, shunts, and stents, posing a potential source of infection for patients. ${ }^{32-34}$ We tested various materials and found that C. albicans could form biofilms on plastic, glass and stainless steel materials with OD595 values of the resulting biofilms of $3.907 \pm 0.111,3.799 \pm 0.166$, and $0.741 \pm$ 0.064 , respectively. The ability to form biofilms on plastic polypropylene and stainless steel was equivalent $(\mathrm{P}>$ $0.05)$, with the two groups significantly different from the glass group $(\mathrm{P}<0.05)$. This may reflect the higher surface roughness of plastics and stainless steel compared to glass, so that $C$. albicans can more easily be adsorbed on their surface. ${ }^{35}$ C. albicans exhibited the strongest biofilm formation ability on polypropylene materials, suggesting that $C$. albicans is more likely to form biofilms on polypropylene materials, which will present a significant health risk. To further investigate biofilm formation, we used 96-well plates and test tubes made of polypropylene to cultivate strains for experiments.

\section{Inhibitory Effects of Cordycepin on the Formation of $C$. albicans Biofilm}

Biofilm formation was measured by crystal violet staining. Cordycepin showed significant inhibition on the biofilm formation of $C$. albicans, with a significant increase in inhibition with increase of cordycepin concentration (Figure 2A). The formation of $C$. albicans biofilm was reduced by $68.45 \%$ in the presence of $0.125 \mathrm{mg} / \mathrm{mL}$ of cordycepin compared with the control group, indicating effective inhibition of $C$. albicans biofilm formation at this concentration. For concentrations of 0.032 and $0.016 \mathrm{mg} /$ $\mathrm{mL}$, cordycepin had no effect on the growth of the strain but inhibited the formation of biofilm by $46.52 \%$ and $28.22 \%$, respectively.

\section{Eradicating Effects of Cordycepin on Pre-Formed Biofilms of $C$. albicans}

The structure of mature biofilms is firm, stable, and not easily damaged, making it difficult for generic drugs to reduce or eliminate mature biofilms. We found that the ability of cordycepin to eradicate pre-formed biofilms of C. albicans was concentration-dependent, which meant that the higher the concentration, the stronger the scavenging effect became (Figure 2B). At a concentration of $0.5 \mathrm{mg} / \mathrm{mL}$, the eradication percentage was $59.14 \%$, significantly improved compared with that of $0.125 \mathrm{mg} / \mathrm{mL}$ $(\mathrm{P}<0.05)$. The results indicate that high concentration of cordycepin can effectively eliminate pre-formed biofilms.

\section{Effects of Cordycepin on the Formation and Eradication of Biofilm Observed by CLSM}

CLSM was used to evaluate the effect of cordycepin on biofilm using FDA/PI fluorescent staining. The staining results revealed a much larger number of viable cells in the control group compared to the number of dead cells, with a thick and large biofilm (Figure 3A, B). After treatment with $0.032 \mathrm{mg} / \mathrm{mL}$ of cordycepin, the thickness of biofilm decreased significantly (Figure $3 \mathrm{C}$ and D). At a concentration of $0.125 \mathrm{mg} / \mathrm{mL}$, the thickness of the biofilm and the total amount of cells were significantly reduced, with only a few cells remaining adhered to the cover glass (Figure $3 \mathrm{E}$ and $\mathrm{F})$, indicating that cordycepin $(0.125 \mathrm{mg} / \mathrm{mL})$ effectively disrupts biofilms of $C$. albicans. 

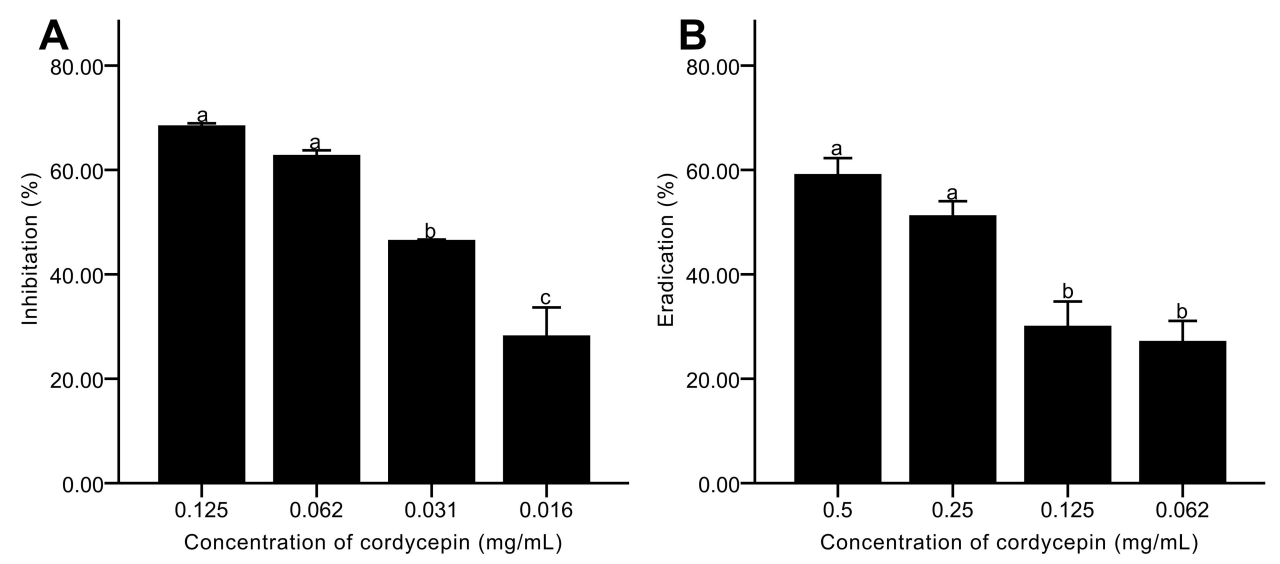

Figure 2 Effects of cordycepin on biofilms of $C$. albicans. (A) Inhibitory effects on biofilm formation; (B) Eradicating effects on mature biofilms. Error bars represent the standard deviations, and different letters represent statistical differences among bars $(n=3, P<0.05)$.

After treatment of the pre-formed biofilms with 0.125 and $0.5 \mathrm{mg} / \mathrm{mL}$ of cordycepin, biofilm thickness and the ratio of living cells to dead cells were obviously decreased compared to those of the pre-formed biofilms that were not treated with cordycepin (Figure 4). With increasing concentration, the changes were more obvious. This indicates that a high concentration of cordycepin can get through the extracellular polymer to enter the biofilm, thus killing C. albicans. Figure 4 shows the partial eradication of mature biofilms with severe damage to biofilm structure.

\section{Effects of Cordycepin on Metabolic Activity of $C$. albicans Biofilm}

During metabolism, microbial biofilms secrete substances including polysaccharides, proteins, nucleic acids, and other substances that are essential for biofilm. XTT colorimetric method was used to evaluate the metabolic activity of $C$. albicans biofilm. ${ }^{36}$ In the biofilm formation process, when the concentrations of cordycepin were at 0.062 , 0.032 , and $0.016 \mathrm{mg} / \mathrm{mL}$, the metabolic activity of biofilm was less than $50 \%$ (Figure 5A). At a concentration of $0.125 \mathrm{mg} / \mathrm{mL}$, there was greater inhibitory effect of cordycepin, with inhibition percentage of $63.11 \%$. The results show that cordycepin inhibits the metabolic activity of C. albicans to decrease the ability of $C$. albicans to form biofilms.

After the biofilm is formed, it is difficult for antifungal drugs to act on microorganisms encapsulated by extracellular matrix. Mature biofilms are highly resistant to fluconazole, amphotericin $\mathrm{B}$, and other drugs. ${ }^{37}$ To assay the effect of cordycepin on the activity of mature biofilms of C. albicans, pre-formed biofilms were exposed to different concentrations of cordycepin. We observed that cordycepin had an obvious effect on mature biofilm of C. albicans (Figure 5B). At concentrations of 0.125 and $0.062 \mathrm{mg} / \mathrm{mL}$, the reduction percentages were only $23.67 \%$ and $12.17 \%$. However, treatment with $0.5 \mathrm{mg} /$ $\mathrm{mL}$ cordycepin concentration resulted in a reduction percentage of $56.08 \%$. As the concentration increased, more cordycepin likely is able to enter the mature biofilms, leading to a significant decrease in metabolic activity.

\section{Effects of Cordycepin on EPS of Biofilm}

EPS was measured using a phenol-sulfuric acid method, and the results are shown in Figure 6. As the concentration of cordycepin increased, the secretion of EPS decreased steadily (Figure 6A). Addition of $0.125 \mathrm{mg} / \mathrm{mL}$ of cordycepin resulted in an EPS inhibition percentage of $60.52 \%$. At lower concentrations, inhibition was less than 50\%, indicating that cordycepin can more effectively reduce EPS secretion in biofilm formation at high concentrations.

After treating the pre-formed biofilms with 0.5 and $0.25 \mathrm{mg} / \mathrm{mL}$ of cordycepin, the EPS reduction percentages were $53.67 \%$ and $36.25 \%$, respectively, and there was a significant difference in EPS secretion $(\mathrm{P}<0.05)$ (Figure 6B). At concentrations of 0.125 and $0.062 \mathrm{mg} /$ $\mathrm{mL}$, the EPS reduction percentage was $20.04 \%$ and $10.44 \%$. The results showed that cordycepin could significantly decrease EPS secretion in pre-formed biofilms, limiting the protective effect of extracellular polysaccharides to maintain biofilm. ${ }^{38}$

\section{Effects of Cordycepin on EPS of Biofilm Observed by CLSM}

In order to further understand the three-dimensional structural changes of biofilms, CLSM was used to observe the 

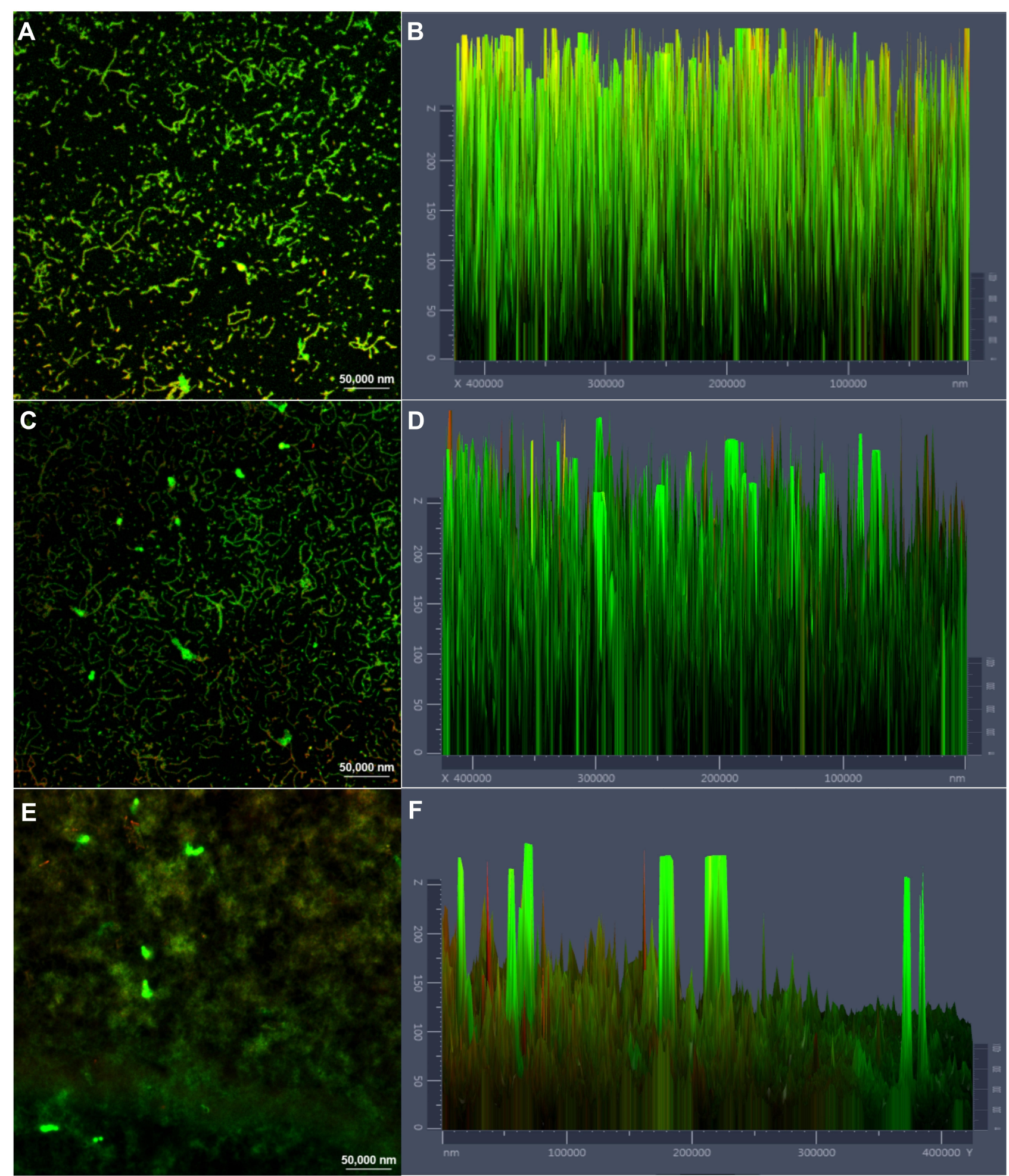

F

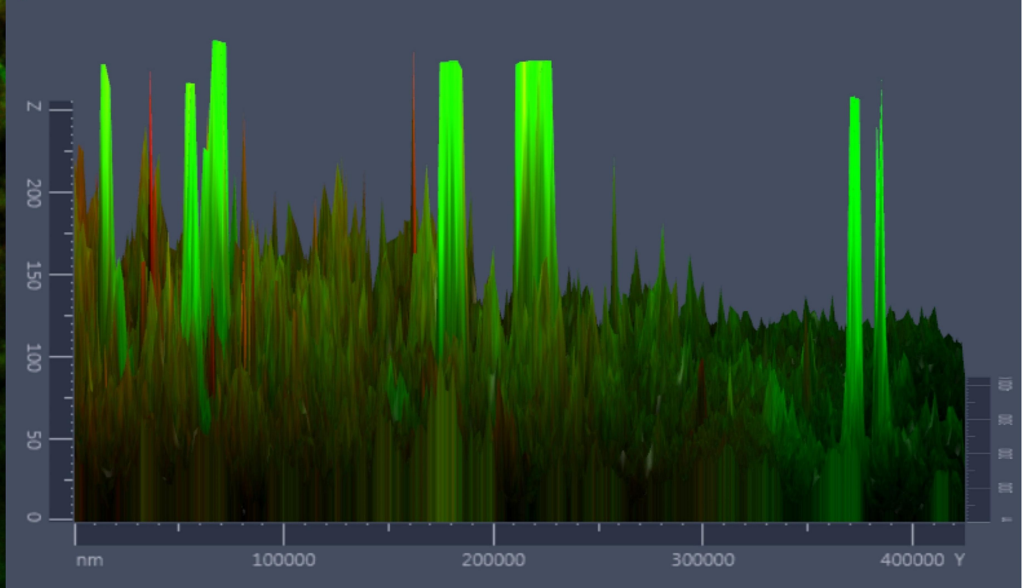

Figure 3 CLSM images of C. albicans biofilm treated with different concentrations of cordycepin. (A), (C) and (E) show the effects of $0,0.03 \mathrm{I}$, and $0.125 \mathrm{mg} / \mathrm{mL}$ of cordycepin on the formation of biofilms and live/dead cells ratio. (B), (D) and (F) show the fluorescence intensities of live (green)/dead (red) cells in biofilms treated with 0 , $0.03 \mathrm{I}$, and $0.125 \mathrm{mg} / \mathrm{mL}$ of cordycepin, respectively. Viable cells appear green due to FDA staining, and cells with damaged membranes appear red due to PI staining.

distributions of EPS and dead cells. ${ }^{22}$ Staining results revealed that the polysaccharides in the untreated biofilm were densely distributed and adsorbed on the coverslip in a lump (Figure 7A). After treatment with $0.032 \mathrm{mg} / \mathrm{mL}$ of cordycepin, there was decreased fluorescence intensity of EPS (Figure 7C). The EPS treated with $0.125 \mathrm{mg} / \mathrm{mL}$ of 


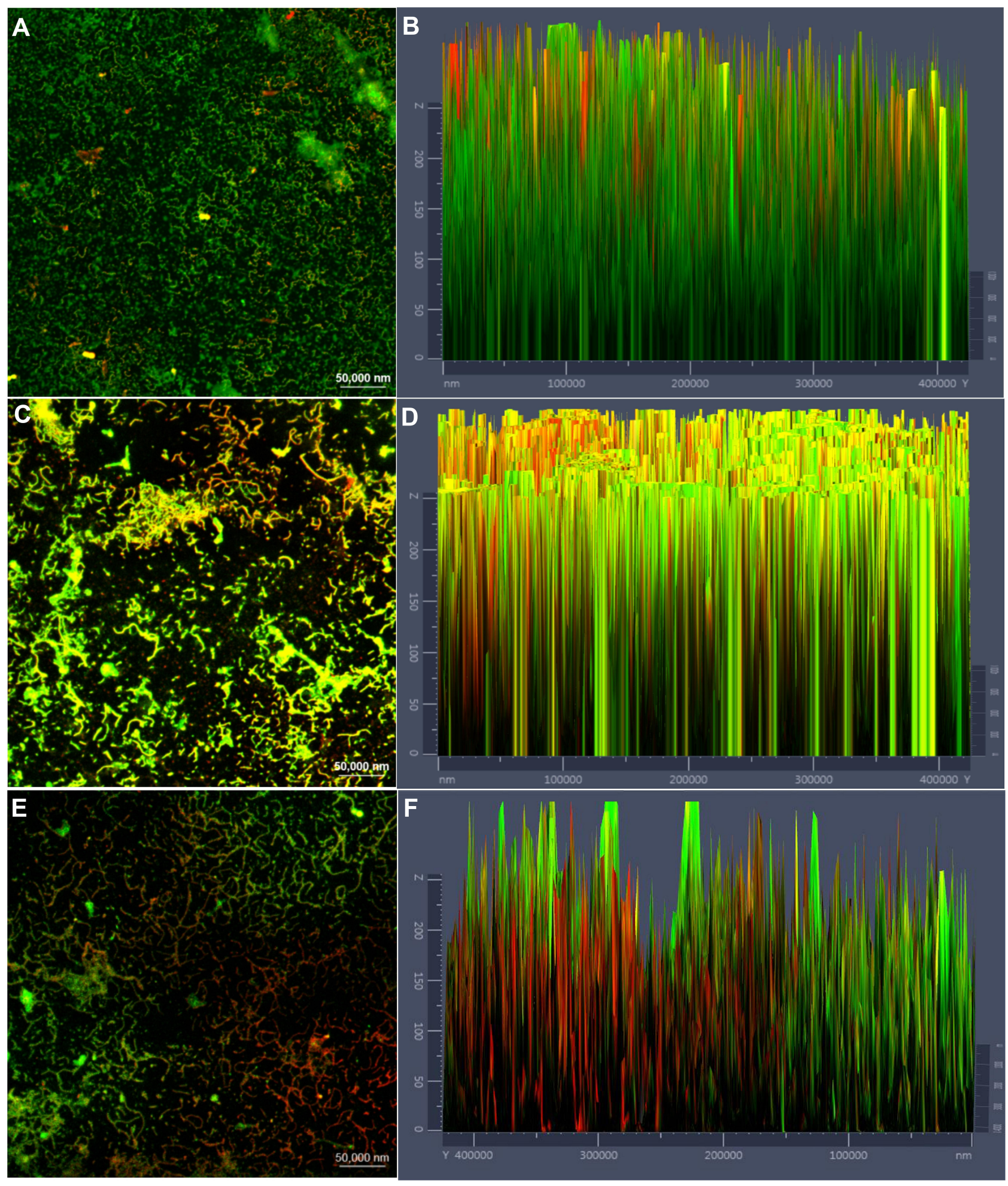

Figure 4 Changes of mature biofilms and live/dead cells before and after cordycepin treatment. (A), (C) and (E) show the effects of $0,0.125$, and $0.5 \mathrm{mg} / \mathrm{mL}$ of cordycepin on the eradication of mature biofilms and live/dead cells. (B), (D) and (F) show the fluorescence intensities of live (green)/dead (red) cells in biofilms treated with $0,0.125$, and $0.5 \mathrm{mg} / \mathrm{mL}$ of cordycepin, respectively. Viable cells appear green due to FDA staining, and cells with damaged membranes appear red due to PI staining. 

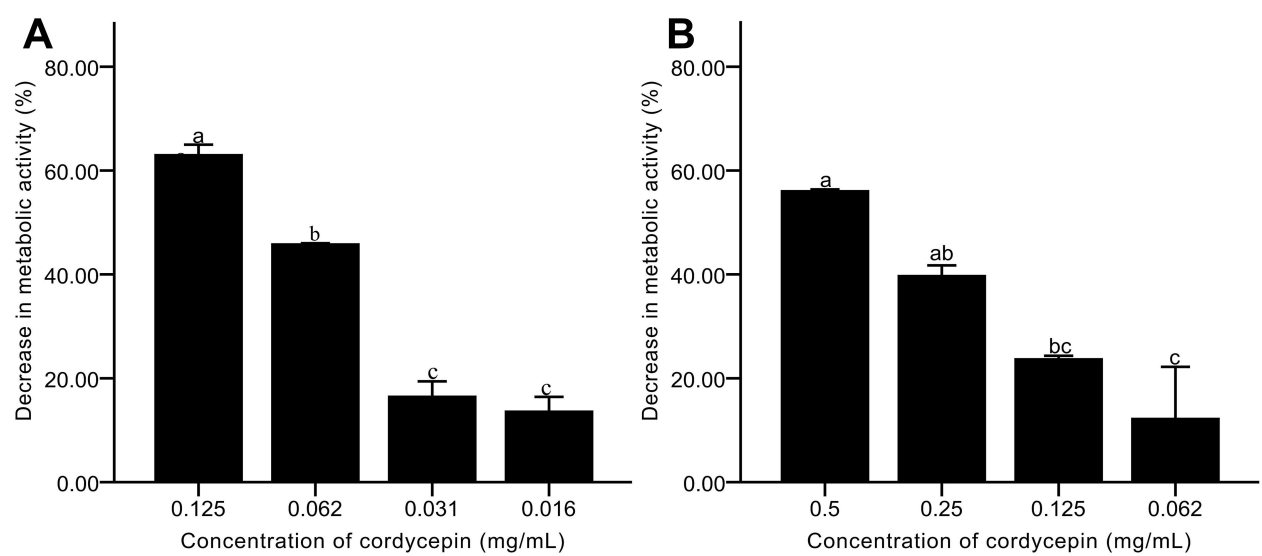

Figure 5 Effects of cordycepin on the metabolic activity of $C$. albicans biofilm. (A) Effects on biofilm formation; (B) Effects on mature biofilms. Error bars represent the standard deviations, and different letters represent statistical differences among bars $(n=3, P<0.05)$.
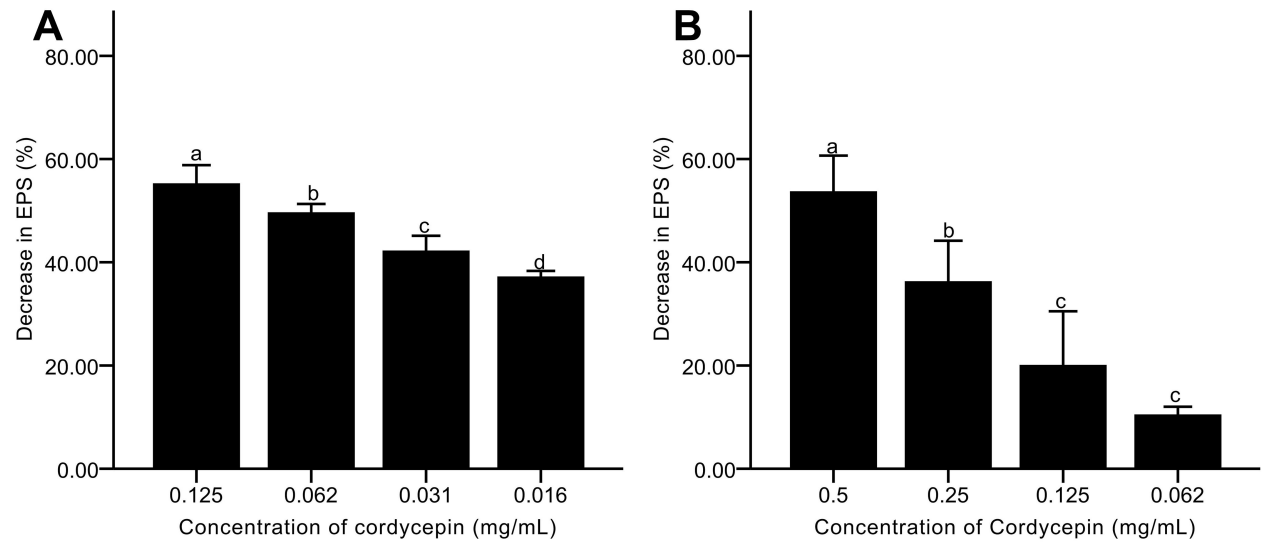

Figure 6 Effects of cordycepin on EPS secretion of C. albicans biofilm. (A) Effects on EPS secretion in biofilm formation; (B) Effects on EPS secretion in mature biofilms. Error bars represent the standard deviations, and different letters represent statistical differences among bars $(n=3, P<0.05)$.

cordycepin exhibited a loose distribution, with obvious differences from treatment with $0.032 \mathrm{mg} / \mathrm{mL}$ of cordycepin (Figure 7E), indicating that cordycepin significantly inhibited the formation of $C$. albicans biofilm.

The effect of cordycepin on the EPS of pre-formed biofilms exhibited the following trend. As the cordycepin concentration increased, the fluorescence intensity of the polysaccharide became weaker, the distribution became sparser, and the number of dead cells increased (Figure 7B, D and F). In the control group without cordycepin treatment, the EPS secreted by $C$. albicans showed strong fluorescence intensity, and the cells were visibly embedded (Figure 7B). After treatment with $0.125 \mathrm{mg} / \mathrm{mL}$ of cordycepin, the content of EPS decreased. Its distribution was not as dense as the control group, and cells were more easily seen (Figure 7D). At a concentration of $0.5 \mathrm{mg} / \mathrm{mL}$, the polysaccharides were loosely distributed with little aggregated into clusters, and significantly increased amount of dead cells (Figure 7F).
Overall, these results indicate that cordycepin can reduce the secretion of EPS, destroy biofilm structure, and affect cell-cell and cell-environment interactions to disrupt biofilms. ${ }^{39-41}$

\section{Effect of Cordycepin on CSH of C. albicans Biofilm}

Adhesion is an important stage in biofilm formation of C. albicans, and $\mathrm{CSH}$ is positively correlated with C. albicans adhesion. ${ }^{42-44}$ We first investigated the effect of cordycepin on CSH of C. albicans during the formation of biofilm. The control group without cordycepin had a relative $\mathrm{CSH}$ value of $51.02 \%$ after $24 \mathrm{~h}$ of culture, indicating a high hydrophobic capacity. With the addition of cordycepin at an initial stage, the relative CSH of the experimental group was reduced. A concentration of $0.125 \mathrm{mg} / \mathrm{mL}$ cordycepin had the biggest effect, reducing relative $\mathrm{CSH}$ to $21.53 \%$ (Figure $8 \mathrm{~A}$ ). We next tested the effect of cordycepin after biofilm formation. To do this, we 


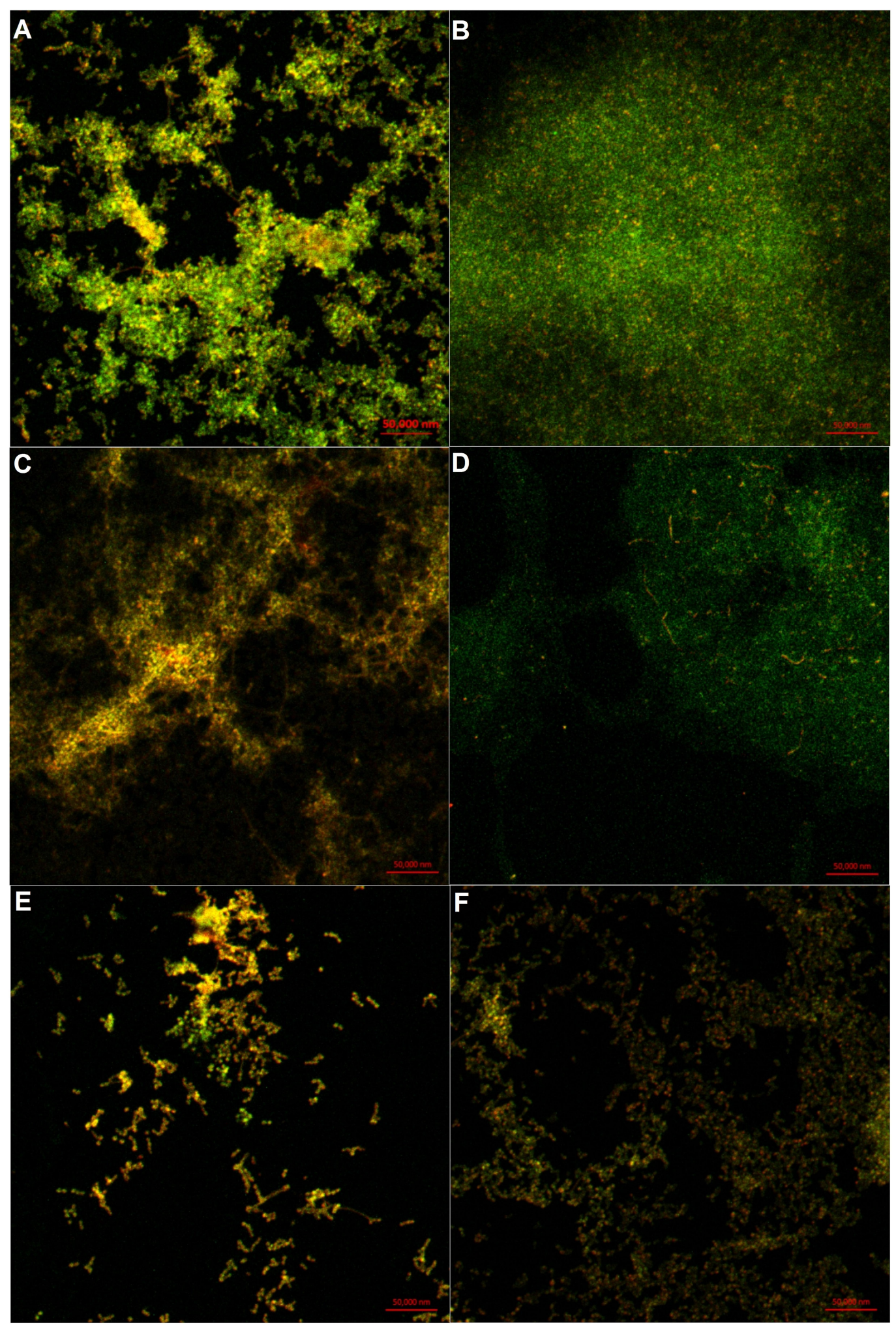

Figure 7 Distribution of polysaccharides and dead cells in cordycepin-treated biofilms. (A), (C) and (E) show the distribution of EPS (green) and dead cells (red) in biofilms treated with $0,0.031$, and $0.125 \mathrm{mg} / \mathrm{mL}$ of cordycepin. (B), (D) and (F) show the distribution of EPS (green) and dead cells (red) in mature biofilms treated with $0,0.125$, and $0.5 \mathrm{mg} / \mathrm{mL}$ of cordycepin. 

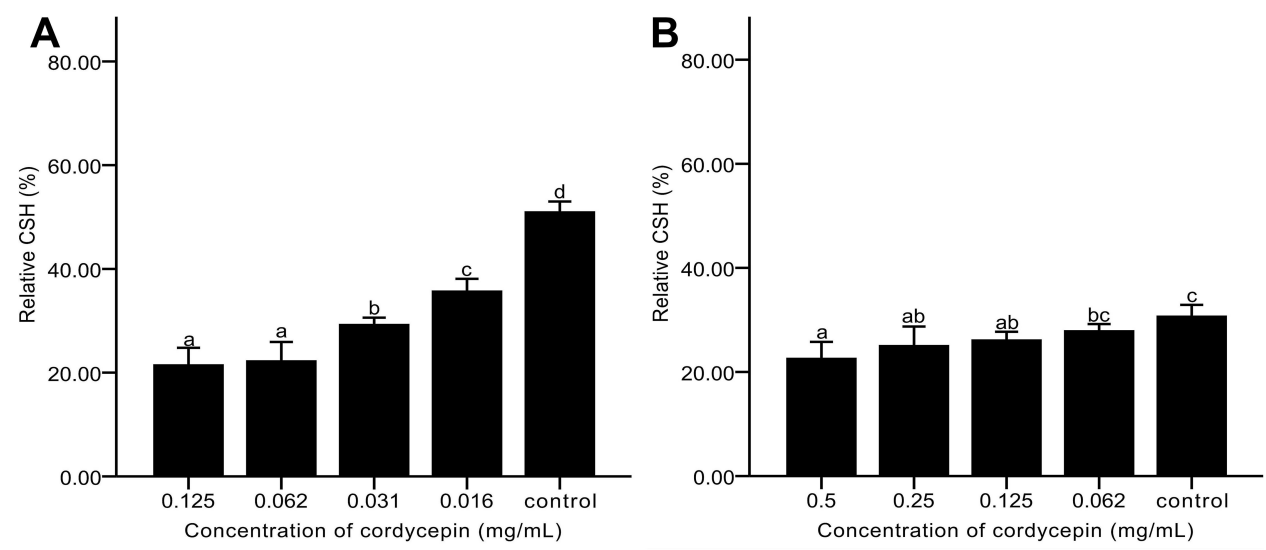

Figure 8 Effects of cordycepin on CSH of C. albicans biofilm. (A) Addition of cordycepin before biofilm formation; (B) Addition of cordycepin after biofilm formation. Error bars represent the standard deviations, and different letters represent statistical differences among bars $(n=3, P<0.05)$.

cultured C. albicans for $24 \mathrm{~h}$, and then added different concentrations of cordycepin. The results showed that the hydrophobicity of the control group without treatment decreased, which may be related to the culture time (Figure $8 \mathrm{~B}) .^{45}$ However, the relative $\mathrm{CSH}$ of this group was higher than the group with the addition of cordycepin. These results indicate that cordycepin can affect the adhesion of $C$. albicans and reduce the likelihood of biofilm formation. The addition of cordycepin before the formation of biofilm had the biggest effect on adhesion.

\section{Acute Toxicity}

To fully evaluate the potential to use cordycepin, the acute toxicity test was performed to determine the $\mathrm{LD}_{50}(50 \%$ of lethal dose) in mice. After sacrificing, the size and appearance of the organs of the mice in the experimental group and the control group were normal, with no obvious lesions such as exudation, hyperplasia, edema, or atrophy in tissues and organs. Therefore, the $\mathrm{LD}_{50}$ of cordycepin was determined to be higher than $500 \mathrm{mg} / \mathrm{kg}$ for mice.

\section{Discussion}

The emergence of resistance to commercial drugs and the toxicity of drugs have limited the effectiveness of current treatment options. ${ }^{4}$ The resistance of pathogens to conventional drugs has multiple mechanisms, such as reducing membrane permeability, encoding multidrug efflux pumps, forming biofilms, and inactivating cell membrane receptors. ${ }^{46-49}$ Therefore, natural, safe and effective antibiotic substitutes are what we have been pursuing. Many natural compounds are reported to have antimicrobial activity against pathogenic microorganisms, including essential oils, curcumin and anthocyanins. ${ }^{50-52}$ Previous studies have shown that essential oils from leaves of Paramignya trimera, Limnocitrus littoralis and Leoheo domatiophorus inhibited the growth of $C$. albicans with MICs of $16 \%, 16 \%$, and $4 \%(\mathrm{v} / \mathrm{v})$, respectively. ${ }^{53,54}$ In this study, we determined the $\mathrm{MIC}_{50}$ of cordycepin against C. albicans standard strains by broth dilution method. The $\mathrm{MIC}_{50}$ of cordycepin was ranging from 0.031 to $0.062 \mathrm{mg} /$ $\mathrm{mL}$, which was higher than that of fluconazole ($\leq 0.002 \mathrm{mg} / \mathrm{mL}$ ), indicating that more cordycepin is needed to achieve the same effect. However, there is a possibility for greater efficacy using cordycepin in combination with other antibiotics. For example, the MIC of eugenol against C. albicans (ATCC 90028) was $625 \mu \mathrm{g} / \mathrm{mL}$, whereas in combination with amphotericin B $(0.05 \mu \mathrm{g} / \mathrm{mL})$, the $\mathrm{MIC}$ of eugenol dropped to $156 \mu \mathrm{g} / \mathrm{mL} .^{55}$ Therefore, the application of cordycepin in combination with other antibiotics will be explored in our future work.

Although natural products and their derivatives have antimicrobial potential, they are still limited as anti-biofilm agents. ${ }^{56}$ To find effective agents to prevent and control biofilm, researchers have started to evaluate small molecules of secondary metabolites that are produced by organisms as a protective response to the external environment. $^{57,58}$ For microorganisms, the secretion of secondary metabolites is a means to compete with other species for resources in the living environments. ${ }^{59}$ After millions of years of evolution and natural selection, microorganisms can not only retain a high degree of selectivity and potency, but also the metabolites they produce sometimes affect the cell envelope, which is lacking in synthetic drugs. ${ }^{60}$ Walkmycin C is produced by Streptomyces sp. strain MK632-100F11 and causes a reduction in Streptococcus mutans biofilms by inhibiting the 
autophosphorylation of histidine kinases VicK and CiaH in a two-component system. ${ }^{61}$

In this study, we found that cordycepin as a nucleoside analogue and a secondary metabolite of $C$. militaris exhibited antifungal activity against Candida species but also effectively inhibited the formation of $C$. albicans biofilm and eradicated mature biofilms. In addition, cordycepin could inhibit the formation of biofilm at a low concentration without affecting significantly cell growth. Another natural nucleoside component, sinefungin can decrease the formation of Streptococcus pneumoniae biofilm by $15 \%$ and $53 \%$ at concentrations of 10 and $50 \mu \mathrm{g} / \mathrm{mL}$. ${ }^{62}$ Pierce et al found that tunicamycin, a nucleoside antibiotic, can inhibit the formation of $C$. albicans biofilm, but has little effect on mature biofilms. ${ }^{37}$

However, the specific anti-biofilm mechanism of cordycepin has not yet been described. In general, antibiofilm agents may prevent biofilm adhesion, anchoring and matrix production by targeting cellular processes or interfering with quorum sensing. ${ }^{20}$ Tapia-Rodriguez reported that biofilm inhibition of carvacrol could be related to the interruption of quorum sensing, potentially achieved by inhibition of the production of pyocyanin and violacein in Pseudomonas aeruginosa and Pseudomonas purple. $^{63}$ Quercetin inhibits the formation of Listeria monocytogenes biofilm by reducing initial attachment and protein accumulation in the matrix. ${ }^{64}$ In addition, the inhibition of $C$. albicans biofilm by tunicamycin can be explained by $\mathrm{N}$-linked glycosylation defects, leading to changes in the properties of the cell wall and surface mannoproteins as well as $\mathrm{CSH}^{37}$ Similarly, we observed that cordycepin significantly decreased metabolic activity, relative $\mathrm{CSH}$, and EPS secretion in a concentrationdependent manner, and these findings were consistent with our CLSM observations.

Mature biofilms are difficult to be eradicated by clinical drugs, such as amphotericin B, fluconazole, flucytosine and itraconazole, which are much less active against $C$. albicans biofilm than planktonic cells. ${ }^{65}$ In this study, cordycepin exhibited a clear eradicating effect on pre-formed biofilms, with an eradication percentage of 59.14\% after treatment with $0.5 \mathrm{mg} / \mathrm{mL}$ cordycepin for $4 \mathrm{~h}$. The results show that cordycepin effectively reduced the secretion of the extracellular matrix, affected the structure of the biofilm, and was able to act on cells wrapped by the extracellular matrix.

Overall, our results indicate that cordycepin, a natural nucleoside component, may be applied as an antifungal and anti-biofilm agent against C. albicans.

\section{Conclusion}

The results showed that the $\mathrm{MIC}_{50}$ of cordycepin against C. albicans was $0.063 \mathrm{mg} / \mathrm{mL}$. At a concentration of $0.125 \mathrm{mg} / \mathrm{mL}$, cordycepin effectively inhibited the formation of biofilms, with an inhibition percentage of $68.45 \%$. At concentrations less than or equal to $0.032 \mathrm{mg} / \mathrm{mL}$, cordycepin had no effect on strain growth but inhibited the formation of biofilm. In addition, a high concentration of cordycepin showed a significant eradicating effect on mature biofilms of $C$. albicans. The inhibiting and eradicating effects of cordycepin were achieved by decreasing the metabolic activity, the living cells, and the hydrophobicity, and by damaging extracellular polysaccharide of biofilm. Acute toxicity was assessed and revealed that the $\mathrm{LD}_{50}$ of cordycepin was higher than $500 \mathrm{mg} / \mathrm{kg}$ for mice. These results indicate that cordycepin provides a new alternative to combat and eliminate fungal biofilms, which is beneficial to design new drugs and reduce drug resistance.

\section{Ethical Approval}

This study has been approved by the Ethics Committee of Wuxi No. 2 People's Hospital 20171115 and has been performed in accordance with the ethical standards laid down in the 1964 Declaration of Helsinki and its later amendments.

\section{Funding}

This work was supported by the Primary Research and Developement Plan Programs of Jiangsu Province (Grant No. 2019633); the Science, Education and Health Engineering-Medical Innovation Team Project of Wu'xi (Grant No. CXTD007).

\section{Disclosure}

The authors report no conflicts of interest in this work.

\section{References}

1. Alves F, Pavarina AC, Mima EGDO, McHale AP, Callan JF. Antimicrobial sonodynamic and photodynamic therapies against Candida albicans. Biofouling. 2018;34(4):357-367. doi:10.1080/ 08927014.2018.1439935

2. Pappas PG, Rex JH, Sobel JD, et al. Guidelines for treatment of candidiasis. Clin Infect Dis. 2004;38(2):161-189. doi:10.1086/380796

3. Vila TVM, Ishida K, de Souza W, Prousis K, Calogeropoulou T, Rozental S. Effect of alkylphospholipids on Candida albicans biofilm formation and maturation. $J$ Antimicrob Chemother. 2013;68 (1):113-125. doi: $10.1093 / \mathrm{jac} / \mathrm{dks} 353$

4. Chavez-Dozal AA, Lown L, Jahng M, Walraven CJ, Lee SA. In vitro analysis of finasteride activity against Candida albicans urinary biofilm formation and filamentation. Antimicrob Agents Chemother. 2014;58(10):5855-5862. doi:10.1128/AAC.03137-14 
5. Lee JH, Kim YG, Gupta VK, Manoharan RK, Lee J. Suppression of fluconazole resistant Candida albicans biofilm formation and filamentation by methylindole derivatives. Front Microbiol. 2018;9:10. doi:10.3389/fmicb.2018.02641

6. Desai JV, Mitchell AP, Andes DR. Fungal biofilms, drug resistance, and recurrent infection. Cold Spring Harb Perspect Med. 2014;4 (10):18. doi:10.1101/cshperspect.a019729

7. Zhu YL, Li CZ, Cui HY, Lin L. Feasibility of cold plasma for the control of biofilms in food industry. Trends Food Sci Technol. 2020;99:142-151. doi:10.1016/j.tifs.2020.03.001

8. Xie Z, Thompson A, Sobue T, et al. Candida albicans biofilms do not trigger reactive oxygen species and evade neutrophil killing. $J$ Infect Dis. 2012;206(12):1936-1945. doi:10.1093/infdis/jis607

9. Tan Y, Ma S, Leonhard M, Moser D, Schneider-Stickler B. beta1,3-glucanase disrupts biofilm formation and increases antifungal susceptibility of Candida albicans DAY185. Int J Biol Macromol. 2018;108:942-946. doi:10.1016/j.ijbiomac.2017.11.003

10. Cunningham KG, Hutchinson S, Manson W, Spring F. Cordycepin, a metabolic product from cultures of Cordyceps militaris (Linn.) link. Part I. Isolation and characterisation. J Chem Soc. 1951;2299-2300. doi:10.1039/JR9510002299

11. Zhou XX, Luo LP, Dressel W, et al. Cordycepin is an immunoregulatory active ingredient of Cordyceps sinensis. Am J Chin Med. 2008;36(5):967-980. doi:10.1142/S0192415X08006387

12. Kondrashov A, Meijer HA, Barthet-Barateig A, et al. Inhibition of polyadenylation reduces inflammatory gene induction. Rna. 2012;18 (12):2236-2250. doi:10.1261/rna.032391.112

13. Zhang P, Huang $\mathrm{C}, \mathrm{Fu} \mathrm{C}$, et al. Cordycepin (3 '-deoxyadenosine) suppressed HMGA2, Twist1 and ZEB1-dependent melanoma invasion and metastasis by targeting miR-33b. Oncotarget. 2015;6 (12):9834-9853. doi:10.18632/oncotarget.3383

14. Zhou XF, Cai GQ, He Y, Tong GT. Separation of cordycepin from Cordyceps militaris fermentation supernatant using preparative HPLC and evaluation of its antibacterial activity as an NAD(+)-dependent DNA ligase inhibitor. Exp Ther Med. 2016;12 (3):1812-1816. doi:10.3892/etm.2016.3536

15. Yeon SH, Kim JR, Ahn YJ. Comparison of growth-inhibiting activities of Cordyceps militaris and Paecilomyces japonica cultured on Bombyx mori pupae towards human gastrointestinal bacteria. $J$ Sci Food Agric. 2007;87(1):54-59. doi:10.1002/jsfa.2669

16. Sugar AM, McCaffrey RP. Antifungal activity of 3 '-deoxyadenosine (cordycepin). Antimicrob Agents Chemother. 1998;42(6):1424-1427. doi:10.1128/aac.42.6.1424

17. Jiang Q, Lou ZX, Wang HX, Chen C. Antimicrobial effect and proposed action mechanism of cordycepin against Escherichia coli and Bacillus subtilis. J Microbiol. 2019;57(4):288-297. doi:10.1007/ s12275-019-8113-z

18. Loewen SK, Ng AML, Mohabir NN, Baldwin SA, Cass CE, Young JD. Functional characterization of a $\mathrm{H}+$ /nucleoside co-transporter (CaCNT) from Candida albicans, a fungal member of the concentrative nucleoside transporter (CNT) family of membrane proteins. Yeast. 2003;20(8):661-675. doi:10.1002/yea.1000

19. Clinical and Laboratory Standards Institute. Reference Method for Broth Dilution Antifungal Susceptibility Testing of Yeasts. 4th Ed. CLSI Standard M27. Wayne, PA, USA: CLSI; 2017.

20. Yssel AEJ, Vanderleyden J, Steenackers HP. Repurposing of nucleoside- and nucleobase-derivative drugs as antibiotics and biofilm inhibitors. J Antimicrob Chemother. 2017;(8):8. doi:10.1093/jac/dkx151

21. Xu DF, Wang YL, Sun LJ, Liu HM, Li JR. Inhibitory activity of a novel antibacterial peptide AMPNT-6 from Bacillus subtilis against Vibrio parahaemolyticus in shrimp. Food Control. 2013;30(1):58-61. doi:10.1016/j.foodcont.2012.07.025

22. Ting X, Zhenlin L, Huan L, Xiang F, Jie W, Qingping Z. Antibacterial activity of food-grade chitosan against Vibrio parahaemolyticus biofilms. Microb Pathog. 2017;110:291-297. doi:10.1016/ j.micpath.2017.07.011
23. Teodoro GR, Gontijo AVL, Salvador MJ, et al. Effects of acetone fraction from Buchenavia tomentosa aqueous extract and gallic acid on Candida albicans biofilms and virulence factors. Front Microbiol. 2018;9. doi:10.3389/fmicb.2018.00647

24. Bazargani MM, Rohloff J. Antibiofilm activity of essential oils and plant extracts against Staphylococcus aureus and Escherichia coli biofilms. Food Control. 2016;61:156-164. doi:10.1016/j.foodcont.2015.09.036

25. Meiling J, Fen Z, Cuixiang W, et al. Evaluation of probiotic properties of Lactobacillus plantarum WLPL04 isolated from human breast milk. J Dairy Sci. 2016;99(3):1736-1746. doi:10.3168/jds.2015-10434

26. DuBois M, Gilles KA, Hamilton JK, Rebers PA, Smith F. Colorimetric method for determination of sugars and related substances. Anal Chem. 1956;28(3):350-356. doi:10.1021/ac60111a017

27. Miao ZK, Lu ZH, Wu HY, et al. Collagen, agarose, alginate, and Matrigel hydrogels as cell substrates for culture of chondrocytes in vitro: A comparative study. $J$ Cell Biochem. 2018;119 (10):7924-7933. doi:10.1002/jcb.26411

28. Klotz SA, Drutz DJ, Zajic JE. Factors governing adherence of Candida species to plastic surfaces. Infect Immun. 1985;50 (1):97-101. doi:10.1016/0162-3109(85)90015-3

29. Sardi JCO, Duque C, Hoefling JF, Goncalves RB. Genetic and phenotypic evaluation of Candida albicans strains isolated from subgingival biofilm of diabetic patients with chronic periodontitis. Med Mycol. 2012;50(5):467-475. doi:10.3109/13693786.2011.633233

30. Panagoda GJ, Samaranayake LP. Relative cell surface hydrophobicity of Candida parapsilosis and Candida albicans. J Dent Res. 1997;76:3130. doi:10.1016/S0278-2391(98)90761-3

31. Clinical and Laboratory Standards Institute. Performance Standards for Antifungal Susceptibility Testing of Yeasts. 2nd Ed. CLSI Supplement M60. Wayne, PA, USA: CLSI; 2020.

32. Hawser SP, Douglas LJ. Resistance of Candida albicans biofilms to antifungal agents in vitro. Antimicrob Agents Chemother. 1995;39 (9):2128-2131. doi:10.1016/0741-8329(95)00034-O

33. Kojic EM, Darouiche RO. Candida infections of medical devices. Clin Microbiol Rev. 2004;17(2):255-267. doi:10.1128/ CMR.17.2.255-267.2004

34. Ramage G, Martinez JP, Lopez-Ribot JL. Candida biofilms on implanted biomaterials: a clinically significant problem. FEMS Yeast Res. 2006;6(7):979-986. doi:10.1111/j.1567-1364.2006.00117.x

35. Cremet L, Corvec S, Batard E, et al. Comparison of three methods to study biofilm formation by clinical strains of Escherichia coli. Diagn Microbiol Infect Dis. 2013;75(3):252-255. doi:10.1016/j. diagmicrobio.2012.11.019

36. Pantanella F, Valenti P, Natalizi T, Passeri D, Berlutti F. Analytical techniques to study microbial biofilm on abiotic surfaces: pros and cons of the main techniques currently in use. Annali di igiene. 2013;25(1):31-42. doi:10.7416/ai.2013.1904

37. Pierce CG, Thomas DP, Lopez-Ribot JL. Effect of tunicamycin on Candida albicans biofilm formation and maintenance. J Antimicrob Chemother. 2009;63(3):473-479. doi:10.1093/jac/dkn515

38. Sutherland IW. Biofilm exopolysaccharides: a strong and sticky framework. Microbiology-(Uk). 2001;147:3-9. doi:10.1099/ 00221287-147-1-3

39. Masuoka J, Hazen KC. Cell wall protein mannosylation determines Candida albicans cell surface hydrophobicity. Microbiology-(Uk). 1997;143:3015-3021. doi:10.1099/00221287-143-9-3015

40. Thomas DP, Bachmann SP, Lopez-Ribot JL. Proteomics for the analysis of the Candida albicans biofilm lifestyle. Proteomics. 2006;6(21):5795-5804. doi:10.1002/pmic.200600332

41. Flemming HC, Wingender J. The biofilm matrix. Nat Rev Microbiol. 2010;8(9):623-633. doi:10.1038/nrmicro2415

42. Luo G, Samaranayake LP. Candida glabrata, an emerging fungal pathogen, exhibits superior relative cell surface hydrophobicity and adhesion to denture acrylic surfaces compared with Candida albicans. APMIS. 2002;110(9):601-610. doi:10.1034/j.16000463.2002.1100902.x 
43. Pompilio A, Piccolomini R, Picciani C, D’Antonio D, Savini V, Di Bonaventura G. Factors associated with adherence to and biofilm formation on polystyrene by Stenotrophomonas maltophilia: the role of cell surface hydrophobicity and motility. FEMS Microbiol Lett. 2008;287(1):41-47. doi:10.1111/j.1574-6968.2008.01292.x

44. Samaranayake YH, Wu PC, Samaranayake LP, So M. Relationship between the cell surface hydrophobicity and adherence of Candida krusei and Candida albicans to epithelial and denture acrylic surfaces. APMIS. 1995;103(10):707-713. doi:10.1111/j.16990463.1995.tb01427.x

45. Hazen KC, Plotkin BJ, Klimas DM. Influence of growth conditions on cell surface hydrophobicity of Candida albicans and Candida glabrata. Infect Immun. 1986;54(1):269-271. doi:10.1007/ BF02017714

46. Bolla JM, Alibert-Franco S, Handzlik J, et al. Strategies for bypassing the membrane barrier in multidrug resistant Gram-negative bacteria. FEBS Lett. 2011;585(11):1682-1690. doi:10.1016/j. febslet.2011.04.054

47. Usai D, Donadu MG, Bua A, et al. Enhancement of antimicrobial activity of pump inhibitors associating drugs. J Infect Dev Ctries. 2019;13(2):162-164. doi:10.3855/jidc.11102

48. Baral B, Mozafari MR. Strategic moves of "superbugs" against available chemical scaffolds: signaling, regulation, and challenges. ACS Pharmacol Transl Sci. 2020;3(3):373-400. doi:10.1021/ acsptsci.0c00005

49. Donadu MG, Usai D, Marchetti M, et al. Antifungal activity of oils macerates of North Sardinia plants against Candida species isolated from clinical patients with candidiasis. Nat Prod Res. 2019:1-5. doi:10.1080/14786419.2018.1557175.

50. Donadu MG, Le N T, Ho D V, et al. Phytochemical compositions and biological activities of essential oils from the leaves, rhizomes and whole plant of Hornstedtia bella Skornick. Antibiotics. 2020;9(6). doi:10.3390/antibiotics9060334

51. Adamczak A, Ozarowski M, Karpinski TM. Curcumin, a natural antimicrobial agent with strain-specific activity. Pharmaceuticals. 2020;13:7. doi:10.3390/ph13070153

52. Lacombe A, Wu VC, White J, Tadepalli S, Andre EE. The antimicrobial properties of the lowbush blueberry (Vaccinium angustifolium) fractional components against foodborne pathogens and the conservation of probiotic Lactobacillus rhamnosus. Food Microbiol. 2012;30(1):124-131. doi:10.1016/j.fm.2011.10.006

53. Le N T, Ho D V, Quoc Doan T, et al. In vitro antimicrobial activity of essential oil extracted from leaves of Leoheo domatiophorus Chaowasku, D.T. Ngo and H.T. Le in Vietnam. Plants. 2020;9(4). doi: $10.3390 /$ plants 9040453
54. Le N T, Ho D V, Quoc Doan T, et al. Biological activities of essential oils from leaves of Paramignya trimera (Oliv.) Guillaum and Limnocitrus littoralis (Miq.) Swingle. Antibiotics. 2020;9(4). doi:10.3390/antibiotics9040207

55. Khan SN, Khan S, Misba L, Sharief M, Hashmi A, Khan AU. Synergistic fungicidal activity with low doses of eugenol and amphotericin B against Candida albicans. Biochem Biophys Res Commun. 2019;518(3):459-464. doi:10.1016/j.bbrc.2019.08.053

56. Melander RJ, Basak AK, Melander C. Natural products as inspiration for the development of bacterial antibiofilm agents. Nat Prod Rep. 2020. doi:10.1039/D0NP00022A

57. Proksch P. Defensive roles for secondary metabolites from marine sponges and sponge-feeding nudibranchs. Toxicon. 1994;32 (6):639-655. doi:10.1016/0041-0101(94)90334-4

58. Wulff JL. Ecological interactions of marine sponges. Can J Zool. 2006;84(2):146-166. doi:10.1139/Z06-019

59. Stubbendieck RM, Straight PD. Multifaceted interfaces of bacterial competition. J Bacteriol. 2016;198(16):2145-2155. doi:10.1128/ JB.00275-16

60. Wright GD. Opportunities for natural products in 21 st century antibiotic discovery. Nat Prod Rep. 2017;694-701. doi:10.1039/ c7np00019g

61. Eguchi Y, Kubo N, Matsunaga H, Igarashi M, Utsumi R. Development of an antivirulence drug against Streptococcus mutans: repression of biofilm formation, acid tolerance, and competence by a histidine kinase inhibitor, Walkmycin C. Antimicrob Agents Chemother. 2011;55(4):1475-1484. doi:10.1128/AAC.01646-10

62. Yadav MK, Park SW, Chae SW, Song JJ. Sinefungin, a natural nucleoside analogue of s-adenosylmethionine, inhibits Streptococcus pneumoniae biofilm growth. J Biomed Biotechnol. 2014;2014. doi:10.1155/2014/156987

63. Tapia-Rodriguez MR, Hernandez-Mendoza A, Gonzalez-Aguilar GA, Martinez-Tellez MA, Martins CM, Ayala-Zavala JF. Carvacrol as potential quorum sensing inhibitor of Pseudomonas aeruginosa and biofilm production on stainless steel surfaces. Food Control. 2017;75:255-261. doi:10.1016/j.foodcont.2016.12.014

64. Vazquez-Armenta FJ, Bernal-Mercado AT, Tapia-Rodriguez MR, et al. Quercetin reduces adhesion and inhibits biofilm development by Listeria monocytogenes by reducing the amount of extracellular proteins. Food Control. 2018;90:266-273. doi:10.1016/j. foodcont.2018.02.041

65. Braga PC, Culici M, Alfieri M, Sasso MD. Thymol inhibits Candida albicans biofilm formation and mature biofilm. Int $J$ Antimicrob Agents. 2008;31(5):472-477. doi:10.1016/j.ijantimicag.2007.12.013
Infection and Drug Resistance

\section{Publish your work in this journal}

Infection and Drug Resistance is an international, peer-reviewed openaccess journal that focuses on the optimal treatment of infection (bacterial, fungal and viral) and the development and institution of preventive strategies to minimize the development and spread of resistance. The journal is specifically concerned with the epidemiology of antibiotic resistance and the mechanisms of resistance development and diffusion in both hospitals and the community. The manuscript management system is completely online and includes a very quick and fair peerreview system, which is all easy to use. Visit http://www.dovepress.com/ testimonials.php to read real quotes from published authors. 